\title{
Analysis of Performance Indicators for Sustainable Management of Community Drinking Water Networks in Cameroon
}

\author{
Charlot Moussa1, Mathias Fru Fonteh ${ }^{2,3}$ \\ ${ }^{1}$ Faculty of Agronomy and Agricultural Sciences, University of Dschang, Dschang, Cameroon \\ ${ }^{2}$ College of Technology, University of Bamenda, Bamenda, Cameroon \\ ${ }^{3}$ Water Management Research Unit, Faculty of Agronomy and Agricultural Sciences, University of Dschang, Dschang, Cameroon \\ Email: moussa_charlot@yahoo.fr
}

How to cite this paper: Moussa, C., \& Fonteh, M. F. (2020). Analysis of Performance Indicators for Sustainable Management of Community Drinking Water Networks in Cameroon. Journal of Service Science and Management, 13, 617-635. https://doi.org/10.4236/jssm.2020.133039

Received: January 8, 2020

Accepted: June 27, 2020

Published: June 30, 2020

Copyright $\odot 2020$ by author(s) and Scientific Research Publishing Inc. This work is licensed under the Creative Commons Attribution International License (CC BY 4.0).

http://creativecommons.org/licenses/by/4.0/

\begin{abstract}
The present study on the management of community drinking water networks in Cameroon aims to analyze, using efficiency indicators, the performance of five community water supply networks in the municipalities of Ndu and Kumbo in the North West region, Bandja in the West region and Efoulan and Zoetélé in the South region. The analysis of the said networks was done using technical and financial indicators: primary yield, rate of unpaid invoices, linear distribution loss index, average annual rate renewal network and the maximum connection opening time for new subscribers. The analysis of financial performance was done through the analysis of annual revenues, leading to the conclusion that these six indicators are important for analyzing the performance of community water supply networks. The study demonstrated also the strong influence of overall water consumption, the linear water loss index and annual turnover on the overall performance of the community water supply network.
\end{abstract}

\section{Keywords}

Performance, Indicator, Community Networks, Consumption and Annual Income

\section{Introduction}

Water is a very abundant resource in Cameroon, but its management still remains a problem. INS (2015) highlights that only $44.6 \%$ of people in rural areas have access to good-quality drinking water. The structures are poorly located and when they are put in place, they are not maintained because the transfer of technology has not been ensured. In most cases, the functioning of these water 
points poses the following problems: an insufficient water supply for the populations, a low quantity and quality of the water distributed; all this coupled with a weak capacity to ensure the extension of the network and the repair of destroyed pipes.

These problems are generally resolved by Water Management Committees (WMCs) or "Water Authorities" with little or no formalization, not very functional in most cases (SNV, 2012). Community water supply network belongs to the community, user who creates an association capable of effectively dealing with management problems such as controlling and monitoring water use, preventing contamination of water, carrying out operations and maintenance activities, financing and monitoring the quantity and quality of the water distributed, with a view to ensuring the performance of the system.

The very low availability of data on the operation and maintenance at the level of community water supply network makes it difficult to analyze the performance of community management. To ensure the continued operation and maintenance of these networks, managers must rely on a certain number of indicators to make decisions. Indicators are effective tools for measuring progress, performance, and changes in capacity (OCDE, 2001). In addition, the set of indicators should relate to an end-to-end process to help decision makers monitor, assess, learn, decide and act (WRI, 1998). The interest of this work is to identify, analyze, evaluate and validate them on the basis of sustainability criteria and key performance indicators (KPI) (Klein \& Smith, 2003; Günther, 2007).

The sustainability of a drinking water supply system is assessed on the basis of the functionality indicators (Moussa et al., 2010; Moussa et al., 2011). These are "clearly defined sustainability indicators, with sectoral objectives, which are essential for moving from an approach focused on extending service to one focused on providing a reliable and sustainable service, in all circumstances" (OCDE, 2001). Efficient management is essential for the long-term proper functioning of hydraulic works, and therefore, for the sustainability of water services in rural areas. However, the evaluation of small dispersed community networks, the implementation of systems using the data collected to diagnose problems and allow corrective actions is almost nonexistent in community networks in Cameroon. Hence the importance of identifying a small number of indicators to assess the performance of community water supply network in Cameroon (Pannell \& Glenn, 2000; Riley, 2001; Canneva \& Guérin-Schneider, 2011). Six indicators were analyzed as part of this study: a descriptive indicator of the water service: the maximum opening connection time for new subscribers (MOCT) and four technical indicators: primary yield, rate of unpaid invoices, the linear distribution loss index (LDL) and the average annual network renewal rate (AANRR); and the monthly income over three years made it possible to understand the cost recovery capacity of the community water supply network.

The main objective of this study is to improve the current management of the community water supply network through the analysis of efficient indicators, which make it possible to assess the current performance of drinking water supply systems in Cameroon. 


\section{Materials and Method}

\subsection{Study Area and Sampling}

\subsubsection{Study Zone}

The management of the community water supply network of Ndu Water $\mathrm{Au}$ thority (NWA) and Kumbo Water Authority (KWA) in the North-West regions, that of the Municipality of Bandja in the West region and those of the municipalities of Efoulan and Meyiboto in the South regions were the subject of this study. The in-depth case study was done in the municipality of Ndu which is entirely located in the North West region, whose climate is of the Sudano-Guinean type marked by two seasons and a unimodal rainfall: the dry season of November in mid-March and the rainy season from mid-March to November from 2013 to 2015 . We used detailed data from the network of the urban area of Ndu, where the water supply is managed by the Ndu Water Authority (NWA). The rapid presentation of this community network indicates 8 water catchment areas, 4 of which are functional; 8 functional public standpipes out of 28 , and 572 private connections. The study was conducted in the Laboratory of Water Management, Department of Rural Engineering, Faculty of Agronomy and Agricultural Sciences, University of Dschang, Cameroon.

\subsubsection{Sampling}

The following formula proposed by Fellegi (2003), was used for simple random sampling. Likewise, this formula was used to calculate the sample of the population of Efoulan centre, Bandja and Meyiboto. For NWA and KWA, we used the data available to customer service.

$$
n=\frac{Z^{2} P(1-P)}{e^{2}}
$$

$n=$ sample size.

For a $95 \%$ confidence level $Z$ is equal to 1.96 .

$e$ : margin of error $=5 \%$.

$P$ : the proportion of the population $=50 \%$.

The correction factor is given by the formula:

$$
N^{\prime}=n /(1+n / N)
$$

$N$ is the size of the mother population.

We applied the same formula for the community water supply network of Zoetele and Bandja.

Zoetele: $N^{P}=300$ households.

Bandja: $N=298$ households.

For the Water Authorities of Ndu and Kumbo, we used data from the water service which is as follows:

NWA: $N^{p}=519$ households served.

KWA: $N=3113$ households served.

The total sample size for this study with correction factor for the three regions and the 05 municipalities including 05 community water supply network con- 
cerned is 4399 households. The survey sheets were analyzed and the information processed in the form of tables, graphs, curves and diagrams using Excel 2013 software and SPSS 19.0 for data analysis, with windows 7 Integral Edition.

\subsection{Data Collection}

\subsubsection{Indicators Used to Assess the Performance of Community Water Supply Network}

The first and most relevant indicator is primary yield, which is a technical indicator. It is calculated using the following formula:

$$
\text { Primary yield }(\%)=\frac{\text { Recorded consumed Volume }}{\text { Distributed Volume }} * 100
$$

The linear loss index (LLI) is the second indicator used. It is an indicator that provides information on water losses in a given section of the system. It is an environmental performance indicator because it provides information on water losses. It is obtained by the formula below:

$$
\operatorname{LLI}\left(\mathrm{m}^{3} / \mathrm{Km} \cdot \mathrm{d}\right)=(V d-V c) /(L * 365)
$$

$V d$ : Volume $\mathrm{m}$ is en distribution $\left(\mathrm{m}^{3}\right)$.

$V c$. Total consumed Volume counted $\left(\mathrm{m}^{3}\right)$.

$L$ : Linear network $(\mathrm{km})$.

The third indicator analyzed is the default rate on invoices or contributions. It is calculated using the following formula:

$$
\operatorname{TIF}(\%)=\frac{\text { number of households that did not contribute during the year }}{\text { total number of households expected to contribute }} * 100 \text { (5) }
$$

It makes it possible to analyze the value of the rate of arrears on contributions or on the water bills of the community water supply network.

The fourth indicator is an investment indicator. The average annual network renewal rate.

$\operatorname{AANRR}(\%)=$ Linear total annual renewal/total linear of the network $* 100$

The fifth indicator is the rate of compliance with the maximum connection opening time for new subscribers

$$
\text { RCMCOT }(\%)=\frac{\text { Number of connection openings completed on time }}{\text { Total number of connection openings }} * 100
$$

The sixth indicator is that of annual income (AI), which corresponds to the network's turnover. To calculate this turnover (gross revenue), take the sum of all the water sales invoices, as well as the assets, excluding taxes, issued during an accounting year. The formula corresponds to:

$$
\mathrm{AI}=\text { sales price } \times \text { quantities of } \mathrm{m}^{3} \text { of water sold. }
$$

\subsubsection{Ndu Water Authority Case Study}

This was obtained after a seven months follow-up in the NWA community and three years of data collection. We were thus able to record all the technical and 
financial data of the customer service of this community network.

\subsection{Method of Data Analysis}

This phase consists of entering and checking entry. This computer data processing takes place in five stages: Counting, codification, seizure, data clearance and IT processing, tabulation.

\section{Results}

\subsection{Technical Indicators}

An analysis of the technical indicators of the five community networks was made. The aim was to assess the technical performance of the various community water supply network methods using these indicators.

\subsubsection{Primary Yield}

Among the five indicators analyzed, primary yield is a very relevant and easy to use as an indicator by leaders and managers of water supply network. It is a technical indicator which is very important because it makes it possible to compare the volume of water and analyze the total water consumption at the network level, which allows the manager to assess the quantities of water consumed from that which has been distributed. This is what we did in the Ndu Water Authority network case study in detail.

\section{1) Analysis of monthly household water consumption}

The analysis of the monthly water consumption of households in the Ndu community network is shown below.

Table 1 and Figure 1 show that more than $30 \%$ of households consumed between 1 and $2.9 \mathrm{~m}^{3}$ of water. This same observation is made for consumption of less than $1 \mathrm{~m}^{3}$ over the entire study period. However, less than $1.5 \%$ of households consumed more than $10 \mathrm{~m}^{3}$ of percentage of households' water over the same period.

Table 2 presents the descriptive statistics of the average monthly water consumption. Maximum water consumption over the entire study period varies between $285 \mathrm{~m}^{3}$ (April) and $410 \mathrm{~m}^{3}$ (June). The highest average water consumption $\left(3.02 \pm 0.56 \mathrm{~m}^{3}\right)$ was obtained in April followed by that of March (2.86 \pm $\left.0.23 \mathrm{~m}^{3}\right)$. The lowest average water consumption $\left(1.04 \pm 0.12 \mathrm{~m}^{3}\right)$ was recorded in May. The values of the coefficients of variation of monthly water consumption are very high, thus indicating a large dispersion of water consumption between households on the average. However, January and March have the same variation coefficient of (178\%).

The values of the standard deviations of monthly household water consumption show strong dispersions compared to the averages. In addition, with regard to Figures 2-4 below, the distributions of consumption are not normal. However, the dispersion was higher in April with a value of 12.71 compared to its average value of $3.02 \pm 0.56 \mathrm{~m}^{3}$. This period corresponds to the start of the rainy season. 
Table 1. Percentages of households by monthly water consumption interval.

\begin{tabular}{ccccccc}
\hline Month & \multicolumn{6}{c}{ Water consumption interval $\left(\mathrm{m}^{3}\right)$} \\
\hline January & 20.77 & 54.38 & 18.53 & 3.87 & 1.83 & 0.61 \\
February & 23.87 & 36.09 & 24.06 & 12.03 & 2.76 & 1.18 \\
March & 22.61 & 30.41 & 28.07 & 13.45 & 4.29 & 1.17 \\
April & 22.03 & 37.43 & 23.00 & 12.28 & 4.29 & 0.97 \\
May & 40.86 & 52.92 & 3.70 & 1.17 & 0.58 & 0.78 \\
June & 24.56 & 66.40 & 6.29 & 0.59 & 1.38 & 0.79 \\
July & 33.79 & 60.71 & 4.12 & 0.27 & 0.55 & 0.55 \\
\hline
\end{tabular}

Table 2. Descriptive analysis of average monthly water consumption $\left(\mathrm{m}^{3}\right)$ of households.

\begin{tabular}{ccccccccc}
\hline Month & Interval & Minimum Maximum & Median & Average & Error Std & Dif type & CV (\%) \\
\hline January & 70 & 0 & 70 & 2.0 & 2.01 & 0.16 & 3.58 & 178 \\
February & 103 & 0 & 103 & 2.0 & 2.69 & 0.26 & 5.77 & 215 \\
March & 101 & 0 & 101 & 2.0 & 2.86 & 0.23 & 5.08 & 178 \\
April & 285 & 0 & 285 & 2.0 & 3.02 & 0.56 & 12.71 & 421 \\
May & 49 & 0 & 49 & 1.0 & 1.04 & 0.12 & 2.81 & 271 \\
June & 41 & 0 & 41 & 1.0 & 1.42 & 0.13 & 2.99 & 211 \\
July & 70 & 0 & 70 & 1.0 & 1.16 & 0.20 & 3.87 & 334 \\
\hline
\end{tabular}

$\mathrm{CV}=$ coefficient of variation. (When $\mathrm{CV}<15 \%$ the variation is small, $15 \%<\mathrm{CV}<35 \%$ average variation, $\mathrm{CV}>35 \%$ high variation).

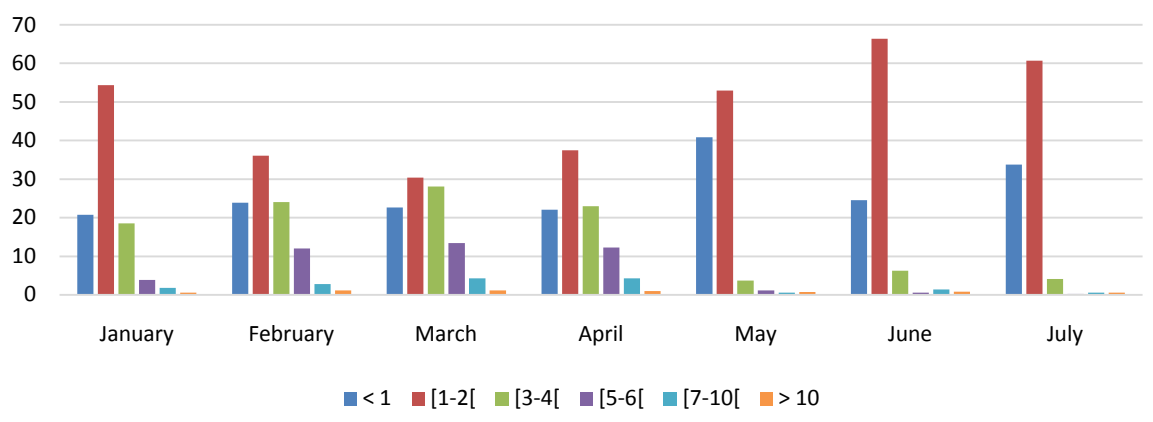

Figure 1. Percentages of households by monthly water consumption interval $\left(\mathrm{m}^{3}\right)$.

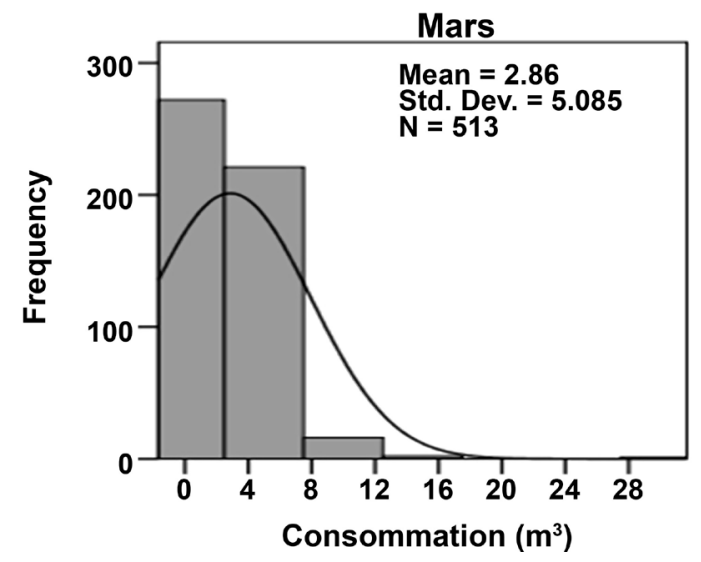

Figure 2. Household water distribution in March. 


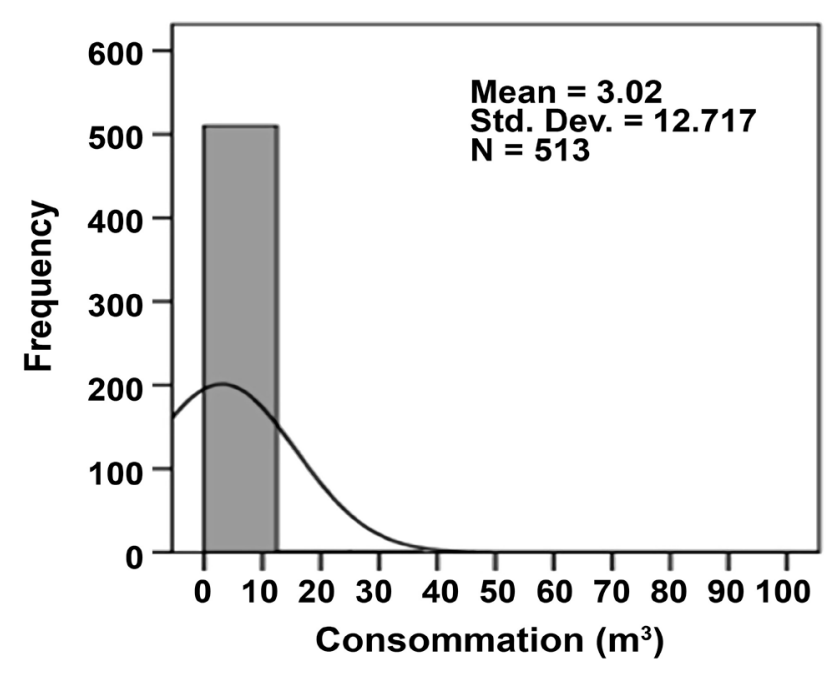

Figure 3. Household water distribution in April.

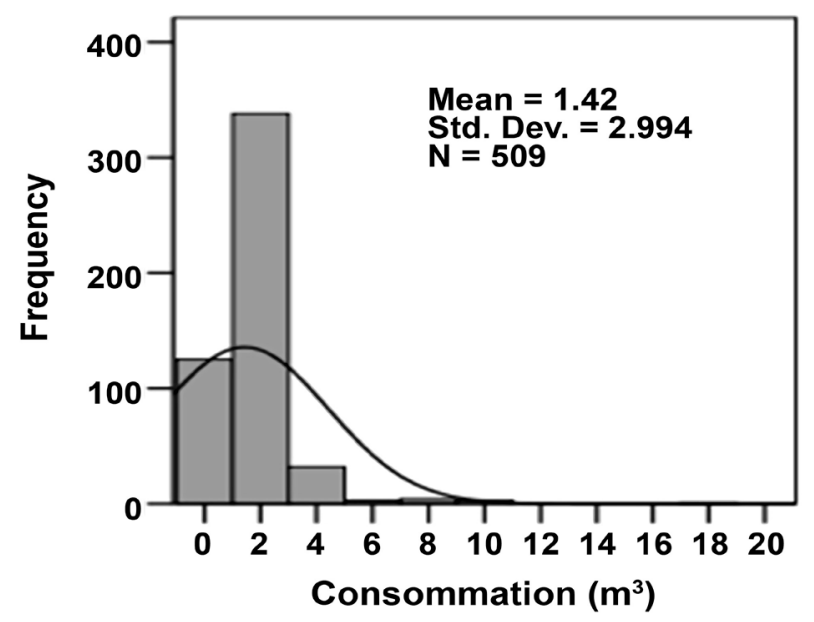

Figure 4. Household water distribution in June.

\section{2) Analysis of water consumption per quarter}

It appears that the Serngwa, Njipkfu, Mbalele quarters respectively have the highest average water consumption values $\left(3.57 \pm 1.43 \mathrm{~m}^{3} ; 3.51 \pm 0.68 \mathrm{~m}^{3} ; 3.04 \pm\right.$ $\left.0.34 \mathrm{~m}^{3}\right)$. The Nsafu quarter has the lowest average water consumption $0.98 \pm$ $0.12 \mathrm{~m}^{3}$. The descriptive analysis of water consumption per quarter shows that the Serngwa quarter has the highest maximum value $\left(285 \mathrm{~m}^{3}\right)$ while the Nsakfu, Palisha, Mburgvu quarters respectively have the lowest maximum value $\left(5 \mathrm{~m}^{3}, 6\right.$ $\mathrm{m}^{3}$ and $8 \mathrm{~m}^{3}$ ). The variation coefficients of the different water consumption show dispersions of strong water consumption on the average in each quarter. The Serngwa district has the highest CV (579.41\%) compared to the Mburgvu district which has the lowest CV $(89.62 \%)$. The analysis of standard deviations confirms these strong dispersions of water consumption on the average. The Serngwa district has the highest dispersion value (20.68) compared to its average which is $3.57 \pm 1.43 \mathrm{~m}^{3}$. However, the analysis of variance shows that there is a significant difference in water consumption among the districts $(P=0.002<$ 
5\%). The separation of averages shows that the Serngwa and Njipkfu districts have the highest water consumption values followed by the Mbalele district. The Mbacourt, Mburgvu, Njipluh, Njiptop, Nseh-O-Doh, Old Market and Palisha districts have the same water consumption. As well as the Kuya, Mbakfu, Njiningo districts. Average water consumption in the Nsakfu district is the lowest as compared to the other districts.

Table 3 shows that the primary yield obtained is good for the three small community water supply network of Meyiboto, Efoulan and Bandja, since it is between $65 \%$ and $96.66 \%$. Those of the Ndu and Kumbo Water Authorities are average between $50 \%$ and $60 \%$ respectively.

Table 3. Primary yield of different community networks.

\begin{tabular}{cc}
\hline Community network & Percentage \\
\hline Meyiboto & $66.67 \%$ \\
Efoulan & $96.66 \%$ \\
Bandja & $70 \%$ \\
NWA & $50 \%$ \\
KWA & $60 \%$ \\
\hline
\end{tabular}

\subsubsection{Linear Loss Index (LLI)}

Table 4 shows the Linear Loss Index (LLI) of the three networks of Méyiboto, Efoulan, have a value less than $0.25 \mathrm{~m}^{3} / \mathrm{Km} \cdot \mathrm{d}$. These values therefore correspond to a low level of water loss which is the characteristic of new networks. Méyiboto, Efoulan, networks are relatively new with less than 10 years of existence. However, LLI of NWA and KWA are greater than $0.25 \mathrm{~m}^{3} / \mathrm{Km} \cdot \mathrm{d}$. The two networks have a significant level of water loss which is respectively $0.4 \mathrm{~m}^{3} / \mathrm{Km} \cdot \mathrm{d}$ and $0.3 \mathrm{~m}^{3} / \mathrm{Km} \cdot \mathrm{d}$. These values are also acceptable, but the network must be renewed imperatively, because they are over 30 years old. The amortization period of a pipeline is between 30 and 50 years and, it is important to calculate the renewal indicator for the network of NWA and KWA which must be between $2 \%$ to $3.3 \%$ per year to be taken into account, if these two networks do not want simply end their drinking water distribution activities.

Table 4. Linear Loss Index (LLI) of different networks.

\begin{tabular}{ccccc}
\hline Quarter & $V d$ & $V c$ & $L$ & LDLI $\left(\mathrm{m}^{3} / \mathrm{Km} / \mathrm{d}\right)$ \\
\hline Méyiboto & 9 & 6 & 4.95 & 0.002 \\
Efoulan & 15 & 14.5 & 19.3 & 0.00007
\end{tabular}

\subsubsection{Unpaid Invoice Rate}

This indicator assesses the cost recovery capacity of community networks.

1) Analysis of the payment of water consumption invoices by quarter

It appears that the quarters of Njipluh, Mbacout and Serngwa respectively have the highest amounts (359,250 FCFA, 291,750 FCFA, 186,750 FCFA) com- 
pared to the Palisha quarters which records the lowest amount (10,000 FCFA). The descriptive analysis shows that the Serngwa, Njipkfu and Mbalele neighborhoods have the highest average values respectively compared to the Nsakfu neighborhood which has the lowest average amount.

However, the variation coefficients are high, thus showing large dispersions between bill payments on the whole. The Serngwa and Njipkfu districts have the highest CVs respectively (578.74\%; 283.03\%). The values of the standard deviations of the payments of the invoices of water consumption show high dispersions on the whole. Serngwa district records the highest dispersion with a value of 5171.25 compared to its average value of $893.54 \pm 357.70$ FCFA).

\section{2) Analysis of unpaid bills for water consumption per quarter}

It appears that the Mbacout, Njipkfu and Njipluh quarters respectively record the highest amounts of unpaid bills for water consumption (85,601 FCFA, 74,250 FCFA, 56,700 FCFA). The Palisha district records the lowest amount (250 FCFA). The descriptive analysis shows that the Njipkfu, Old Market and Mbalele quarters respectively have the highest average values (1455.88 \pm 585,432 FCFA, $1375.00 \pm 362,900$ FCFA, $1357.14 \pm 346,404$ FCFA) compared to the Nsakfu quarter which has the lowest average value ( $343.75 \pm 45,745$ FCFA). The values of the coefficients of variation are high, thus showing large dispersions between the unpaid invoices around the averages. The Mbacout district has the highest variation coefficient (VC) (311.74\%) compared to the Nsakfu quarter, which has the lowest value (37.64\%). The values of the standard deviations of the unpaid bills for water consumption show high dispersions around the averages. The Njipkfu quarter records the highest dispersion with a value of 4180.81 compared to its average value of $1455.88 \pm 585.432$ FCFA.

Figure 5 and Figure 6 below show the Njipkfu and Mbacout neighborhoods, which record the highest amounts of unpaid water consumption bills, show that the unpaid water consumption bills per district do not follow the normal distribution.

The results of the analysis of the variance in Table 5 show that there is no significant difference between the averages of unpaid invoices per district $(\mathrm{F}=$ $0.387>0.05$ ). Also, the value of LSD shows that the averages of these invoices are not significantly different. Table 6 shows that cost recovery in small networks is a problem linked to the high rate of unpaid dues.

Table 6 shows the unpaid rates on contributions from the community networks of Méyiboto, Bandja and Efoulan.

\subsubsection{The Average Annual Network Renewal Rate (ANRR)}

The average annual networks renewal rate of the community is thus presented.

Table 7 shows the value of the average annual network renewal rate is zero in Meyiboto. This network has never been renovated. However, that of Efoulan has undergone minor renovations. On the other hand, it was difficult to calculate the AANRR of the Bandja, NWA and KWA networks because no data was available in these three networks on renewal. 


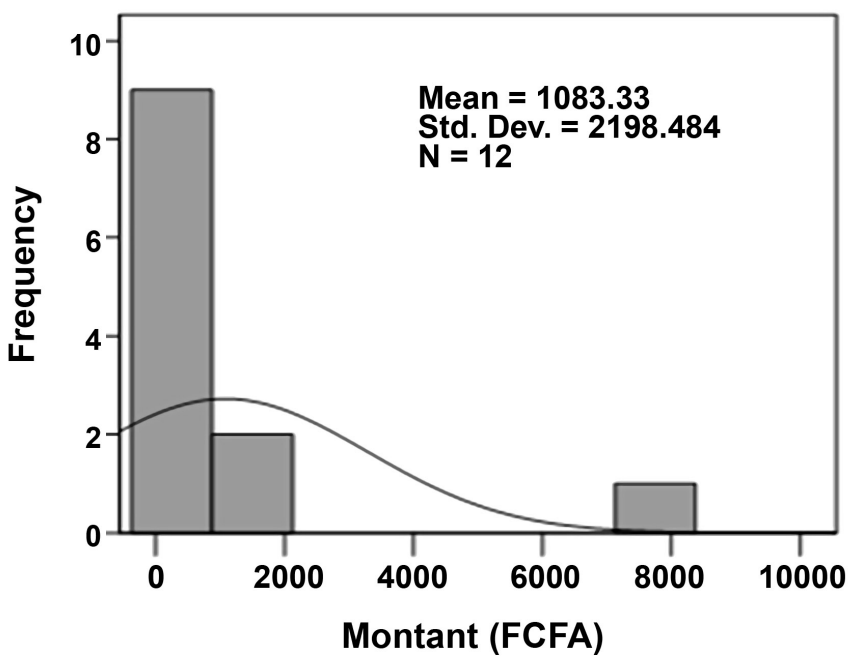

Figure 5. Distribution of unpaid invoices for water consumption in the Njipkfu 8 district.

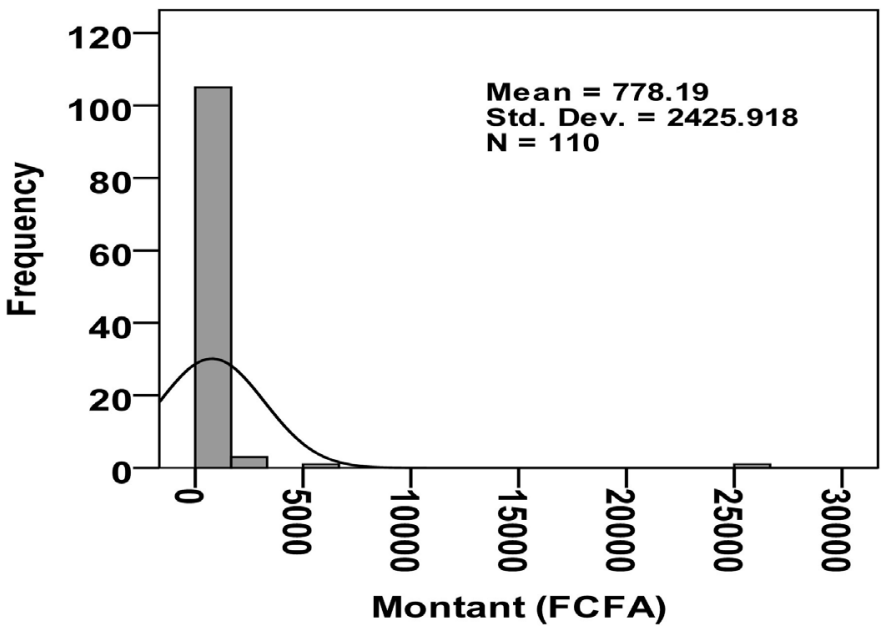

Figure 6. Distribution of unpaid invoices for water consumption in the Mbacout 9 district.

Table 5. Variance analysis of unpaid invoices.

\begin{tabular}{cccccc}
\hline Variate: Amount (F cfa) & \multicolumn{5}{c}{} \\
\hline Source of variation & D.F. & S.S. & M.S. & V.R. & F probability \\
\hline Quarter & 13 & $5.380 \mathrm{E}+07$ & $4.138 \mathrm{E}+06$ & 1.07 & 0.387 \\
Residual & 510 & $1.981 \mathrm{E}+09$ & $3.885 \mathrm{E}+06$ & & \\
Total & 523 & $2.035+09$ & & & \\
\hline
\end{tabular}

Table 6. Unpaid contribution rates.

\begin{tabular}{cc}
\hline Community Network & Percentage rate of unpaid dues \\
\hline Méyiboto & 20.59 \\
Efoulan & 10.34 \\
Bandja & 54.12 \\
\hline
\end{tabular}


Table 7. The average annual networks renewal rate of the community.

\begin{tabular}{cccc}
\hline Quarter & Linear total annual renewal & total linear of the network & AANRR (\%) \\
\hline Efoulan & 12 & 19.348 & 0.062 \\
Méyiboto & 0 & 4.95 & 0.000 \\
\hline
\end{tabular}

\subsubsection{Maximum Connection Opening Time Indicator for New Subscribers (MCOTINS)}

The rate of compliance with the maximum connection opening time for new subscribers is $50 \%$ for Efoulan.

The time taken by a new subscriber to connect to the network as planned by the management committees is two weeks on the average. This time is counted after payment by individuals of the amount contained in the connection estimate established by the management committee. In addition, the connection duration can go beyond two weeks depending on the distance from the home to be connected to the network.

\subsection{Financial Indicators: Analysis of Annual Water Consumption Revenues}

\subsubsection{Monthly Income for the Year 2013}

March has the highest income (CFAF 644,355) compared to November which has the lowest income (78,895 FCFA). The descriptive analysis of income for the same year shows that the highest average income was obtained in January $(5393.95 \pm 868,458$ FCFA) while the lowest was recorded in the month of November $(1038.09 \pm 185,427$ FCFA). The values of the coefficients of variation are high, thus showing wide dispersions between monthly incomes on the averages. The month of September recorded the highest VC (569.23\%). The values of the standard deviations of the monthly incomes confirm these high dispersions on the whole The month of April recorded the highest dispersion with a value of $20,695.405$ compared to its average value of $3635.66 \pm 1,873,674$ FCFA.

\subsubsection{Monthly Income for the Year 2014}

March has the highest income (490,250 FCFA) followed by September $(422,500$ FCFA) and August (408,250 FCFA), compared to the month of November with the lowest income (97,000 FCFA). The descriptive analysis of this income for the same year shows that the highest average was recorded in August (3581.14 $\pm 2,294,406$ FCFA) while the lowest was recorded in November (740.46 $\pm 61,088$ FCFA). The values of the coefficients of variation are high, thus showing a great dispersion between the monthly incomes from water consumption. August and September had the highest VCs (684.07\% and 662.99\%, respectively). The values of the standard deviations of the monthly income from water consumption show high dispersions on the whole. The month of August records the highest dispersion with a value of $24,497,550$ compared to its average value of $3581.14 \pm 2294.406$ FCFA.

\subsubsection{Monthly Income for the Year 2015}

The months of January, June and December respectively present the highest consumption income (389,750 FCFA, 366,100 FCFA and 323,400 FCFA) com- 
pared to the month October with the lowest income (108,600 FCFA). The descriptive analysis of these incomes for this same period shows that the highest average incomes were recorded in January (1855.95 $\pm 269,112$ FCFA) and February (1593.92 $\pm 236,776)$, respectively while the lowest was recorded in October $(551.27 \pm 53,215$ FCFA $)$.

\subsubsection{Change in Annual Revenue from Water Consumption}

The descriptive analysis of annual income Table 8 shows that the year 2014 recorded the highest maximum income (488,000 FCFA). However, Table 9 shows that the year 2013 presents the highest average value of revenues $(12,808.27 \pm 962,330$ FCFA). The values of the variation coefficients are high, thus showing large dispersions of annual income on the whole. The year 2014 records the highest VC of revenues $(284.38 \%)$ and the standard deviation shows that this dispersion is the highest $(27,458.093$ FCFA) for the same year on the average $9655.35 \pm$ 1,457,324 FCFA compared to those of 2013 and 2015. With regard to these results, Figures 7-9 show that the distributions of annual income are not normal.

The use of non-parametric analysis by the Kruskal-Wallis test has been done.

Table 8. Descriptive statistics of the annual income distribution.

\begin{tabular}{|c|c|c|c|c|c|c|c|c|}
\hline & $\mathrm{N}$ & Minimum & Maximum & Total & Average & Std Error. & Diff. type & CV (\%) \\
\hline Income in 2013 & 325 & 250 & 227,205 & $4,162,687$ & $12,808.27$ & 962.330 & $17,348.647$ & 135.45 \\
\hline Income in 2014 & 355 & 250 & 488,000 & $3,427,650$ & 9655.35 & 1457.324 & $27,458.093$ & 284.38 \\
\hline Income 2015 & 432 & 250 & 111,250 & $3,159,550$ & 7313.77 & 420.475 & 8739.413 & 119.49 \\
\hline
\end{tabular}

Table 9. Ranking of average annual revenues from water consumption.

\begin{tabular}{ccc}
\hline Variable & Height $(\mathrm{N})$ & Average Classification (FCFA) \\
\hline Income-2013 & 325 & 678.51 \\
Income-2014 & 355 & 514.83 \\
Income-2015 & 432 & 498.95 \\
\hline
\end{tabular}

Value of $\mathrm{H}=66.76, p=0.05$; Degrees of freedom $=2$; Chi-square $\left(\mathrm{X}^{2}\right)$ probability $<0.001$.

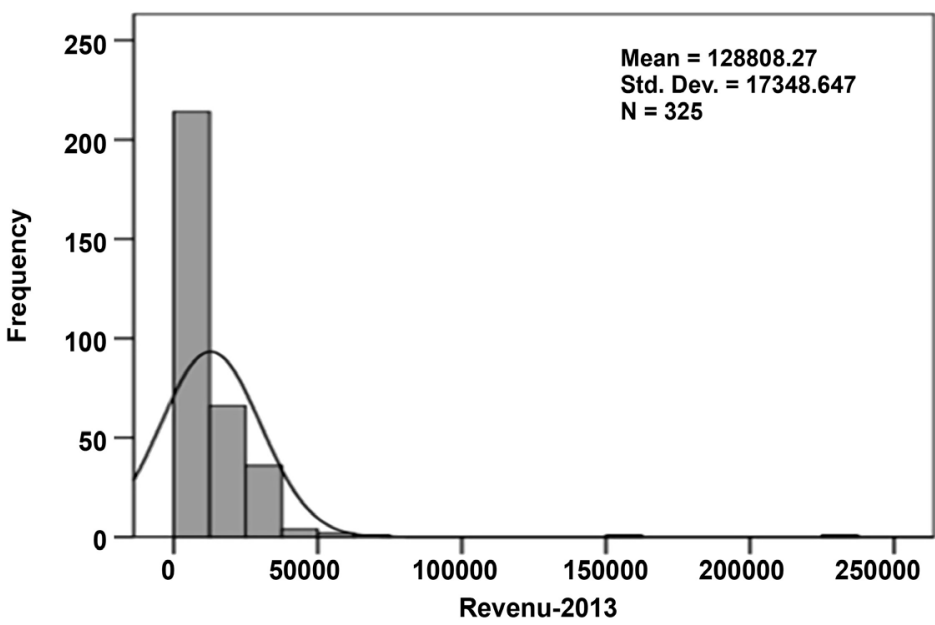

Figure 7. Distributions of water consumption income in 2013. 


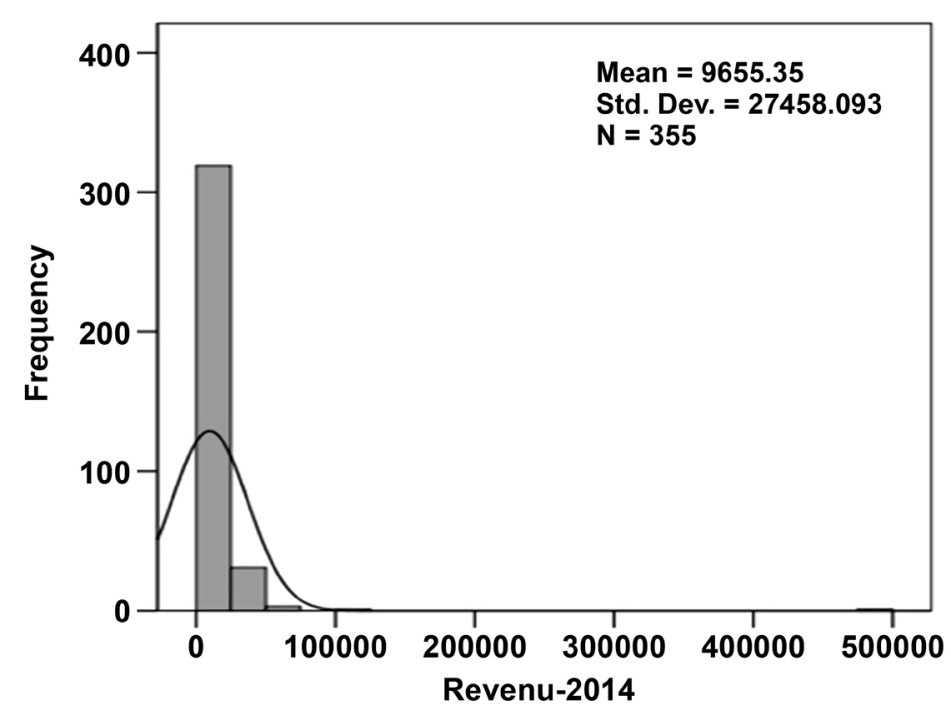

Figure 8. Distributions of water consumption income in 2014.

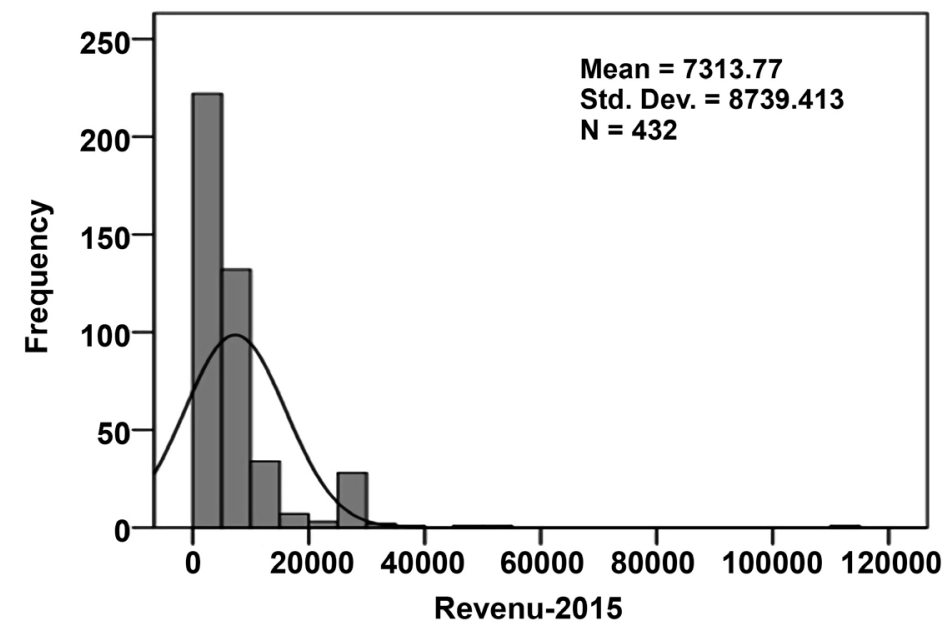

Figure 9. Distributions of water consumption revenues in 2015.

When $\mathrm{X}^{2}<\mathrm{H}$, then the null hypothesis is rejected (Ho), which stipulates that the median values of the average water consumption income are equal and to this end, we accept the alternative hypothesis which stipulates that the median values are significantly different.

\section{Discussion}

The first indicator analyzed in this study is primary yield, since the bulk water transfer is carried out before distribution. It translates the concept of network efficiency, since it compares all of the water consumed, counted with that introduced into the network.

The study of the monthly analysis of water consumption of the community network of Ndu Water Authority Table 1 shows that more than $60 \%$ of households consumed between 0 and $2.9 \mathrm{~m}^{3}$ of water, which corresponds to ordinary households, that is to say, households that do not have modern toilets. On the 
other hand, less than $1.5 \%$ of households consumed more than $10 \mathrm{~m}^{3}$ of water over the same period corresponding to public standpipes. The rest of $38.5 \%$ corresponds to water consumed by private residences (18.5\%) and, elites, public administrations (20\%) who receive water for free. Table 2 shows that the highest average water consumption $\left(3.02 \pm 0.56 \mathrm{~m}^{3}\right)$ which was obtained in April which corresponds to the start of the rainy season, followed by that of the month of March $\left(2.86 \pm 0.23 \mathrm{~m}^{3}\right)$ which corresponds to the end of the dry season. The lowest average water consumption $\left(1.04 \pm 0.12 \mathrm{~m}^{3}\right)$ was recorded in May corresponding to the rainy season which offers alternative sources of water supply to local populations, with a high dispersion in April with a value of $12.71 \mathrm{~m}^{3}$ of water compared to its average value of $3.02 \pm 0.56 \mathrm{~m}^{3}$. The high dispersion of water consumption between households on the average is explained by externalities such as unregistered water volumes which include losses in the production and distribution network which is $0.4 \%$ of $\mathrm{m}^{3} / \mathrm{km} / \mathrm{d}$ in NWA network. However, densely populated quarters such as Serngwa, Njipkfu, Mbalele respectively have the highest average water consumption values $\left(3.57 \pm 1.43 \mathrm{~m}^{3} ; 3.51 \pm 0.68 \mathrm{~m}^{3} ; 3\right.$, $04 \pm 0.34 \mathrm{~m}^{3}$ ). These quarters, which are the most densely populated in the municipality, must have very high volumes of unregistered water users. They are located below the catchment where the supply is through gravity, compared to the Nsafu district located on a hill which has the lowest average water consumption $0.98 \pm 0.12 \mathrm{~m}^{3}$. It is difficult to get water in this area, because a motor pump would have to be used to raise water at that altitude. The analysis of the variance shows that there is a significant difference in water consumption among districts $(P=0.002<5 \%)$. This is explained by the fact that the upper quarters cease to be supplied with water as soon as there is water cut while those located below the water tank continue to be supplied by gravity. The ILP should be raised in densely populated areas that also receive water through gravity.

Table 3 shows the primary yields of the 05 community networks. We see immediately that those of NWA and KWA are the lowest of 50\% and 60\% respectively. These two networks alone represent more than 4000 private subscribers and more than 150 public standpipes. It is safe to say that water consumption influences primary yield. Externalities such as unregistered volumes (losses actually occurred during the journey in the production and distribution network, the unaccounted volume consumed such as the $20 \%$ of consumers of this network who receive water for free, errors in the actual losses and the apparent losses) are all factors that can negatively influence this average primary yield. The three other municipalities of Meyiboto, Bandja and Efoulan respectively have $66.67 \%, 70 \%$ and $96.66 \%$. This primary yield obtained is good for these three community networks of Meyiboto, Efoulan and Bandja, since it is between $65 \%$ and $96.66 \%$. However, these three networks are mainly public standpipes with little private connection.

The second indicator analyzed is that of the Linear Loss Index (LLI). The three DWS networks of Méyiboto, Efoulan, Bandja have a value of less than 0.25 $\mathrm{m}^{3} / \mathrm{Km} \cdot \mathrm{d}$. This value therefore corresponds to a low level of water loss on the 
network; this is the characteristic of new networks. This result is in agreement with the three networks of Méyiboto, Efoulan, Bandja, which are still relatively new with less than 10 years of existence. However, those of NWA and KWA are greater than $0.25 \mathrm{~m}^{3} / \mathrm{Km} \cdot \mathrm{d}$. These two networks have a significant level of water loss: NWA $0.4 \mathrm{~m}^{3} / \mathrm{Km} \cdot \mathrm{d}$ and $\mathrm{KWA} 0.3 \mathrm{~m}^{3} / \mathrm{Km} \cdot \mathrm{d}$. These values are acceptable but the network must be renewed imperatively, because these two networks are over 30 years old. The amortization period of the pipelines is between 30 and 50 years and, it is important to calculate the network renewal indicator for NWA and KWA which must be between $2 \%$ to $3.3 \%$ per year if these two networks do not or would not want to simply stop their drinking water distribution activities.

Throughout this study, we observe a very wide dispersion of the averages around household consumption. This has repercussions on annual income. This is explained by the Linear Unregistered Volume Index (LUVI), which is water that has been produced and is "lost" before reaching the customer. Losses can be real (through leaks, sometimes called physical loss) or apparent (through flight or counting errors, authorized consumption not billed in the case of elites who do not pay for water). High levels of LUVI affect the financial viability of the water system, as well as primary performance. High levels of LUVI can affect the ability of water managers to increase connections and extend service coverage.

The third indicator is the rate of unpaid contributions, which shows that almost $21 \%$ of households supplied by the community network of Meyiboto did not pay their monthly contributions. This state of affairs is linked to the fact that hierarchical links in the village are not respected. The members of the management committee are legitimate because they are installed by the Zoétélé municipality, but the populations have no respect for them. The consequence is the categorical refusal of some households to pay their monthly contributions. This poor collection performance is also due to a mentality in some households with regard to free water. They use water but refuse to pay their annual dues. The unpaid rate is moderate for the municipality of Efoulan because this network is fully supported by the municipality; but it is relatively high (54.12\%) in the municipality of Bandja for the populations using public standpipes compared to those connected to the network. The fact that users do not contribute enough limits the network management committee in its operation. This is why some breakdowns are often prolonged for several days, resulting in water loss due to the lack of financial means to bear the costs of repair.

With regard to the Ndu Water Authority network, the analysis of variance shows that the values of the coefficients of variation are high, thus indicating large dispersions between unpaid invoices on the average. The Mbacout district has the highest CV (311.74\%) compared to the Nsakfu quarter, which has the lowest value (37.64\%). The values of the standard deviations of the unpaid bills for water consumption show high dispersions on the average. The Njipkfu district records the highest dispersion with a value of 4180.81 FCFA compared to its average value of $1455.88 \pm 585,432$ FCFA. Figure 8 and Figure 9 show that unpaid bills for water consumption per district do not follow normal distribu- 
tions. The results of analysis of variance show that there is no significant difference between the means of unpaid invoices per district $(F=0.387>0.05)$. Also, the value of LSD shows that the averages of these invoices are not significantly different.

The fourth indicator is the maximum opening time for new subscribers (MOTNS). Interviews with network subscribers revealed that this period was between 7 and 15 days; which is acceptable, although very rarely observed. Some connections were made up to 01 month after the request accompanied by the equipment necessary for the connection. It should be noted that for a new connection, it is the subscriber who buys the plumbing equipment and the repairers from the management committee take care of the installation. In the case of the community networks of Méyiboto, Efoulan and Bandja, one of the main causes of the delay in connecting new subscribers is the unavailability of the caretakers responsible for the installations. In fact, the village being highly agricultural, the repairers devote most of their time to their plantations and only take care of tasks linked to the community network when they have some free time. Another cause of this delay is the disagreement between the subscriber and the management committee regarding the amount to be paid by the subscriber for the provision of the service, since this amount is defined in a participatory manner but can be renegotiated depending on individual cases.

The fifth indicator is the annual average network renewal rate (AANRR). It is an investment indicator that shows that the value of the average annual network renewal rate is zero in Meyiboto and Bandja, simply because the community network of Meyiboto and Bandja has never been renovated. Indeed, the network is still relatively new and, therefore, its facilities have not yet been renewed. However, that of Efoulan has undergone minor renovations.

The sixth indicator analyzed is the annual income of the community network of Ndu Water Authority. It corresponds to the network turnover (gross revenue). The distribution of monthly income from water consumption for the year 2013 and 2014 of NWA has the highest turnover between 490,250 - 644,355 FCFA compared to November which records the lowest turnover between 78,895 97,000 FCFA. The values of the coefficients of variation are high, thus showing wide dispersions between monthly incomes on the whole. The month of September records the highest CV of between $569.23 \%$ to $684.07 \%$. These values indicate that several years should be compared for a real estimate of the average turnover of a network due to the fact that there are large variations in consumption in general. This is confirmed by the distribution of monthly income from water consumption for the year 2015, which is different from the previous two, of which the months of January, June and December respectively present the highest consumption income (389,750 FCFA, 366,100 FCFA and 323,400 FCFA) compared to the month of October which records the lowest consumption income (108,600 FCFA). However, for the three years of the study, November recorded the highest CV (349.45\%). The descriptive analysis of annual income Table 9 shows that the year 2014 recorded the highest maximum income $(488,000$ 
FCFA). However, the year 2013 presents the highest average value of revenues $(12,808.27 \pm 962,330$ FCFA). The values of the coefficients of variation are high, thus showing large dispersions of the turnover around the means. The year 2014 records the highest CV of revenues (284.38\%) and the standard deviation shows that this dispersion is the highest $(27,458,093)$ for the same year around its average $9655.35 \pm 1,457,324$ FCFA compared to those of 2013 and 2015 .

The nonparametric analysis was done by the Kruskal-Wallis test was used. Thus, according to the ranking of the average annual revenues from water consumption, it appears that there is a significant difference in the median values between the annual revenues for the different years. For this purpose, the year 2013 presents the highest average water consumption income (678.51 FCFA) followed by 2014 (514.83 FCFA) and finally 2013 (496.95 FCFA).

It appears from the various analyzes that there is a strong relationship between water consumption and income in $2013\left(\mathrm{R}^{2}=0.9098\right)$. So when water consumption increases exponentially, monthly income also increases. This same observation is made for the relationship between water consumption and income in $2014\left(\mathrm{R}^{2}=0.9233\right)$. However, for 2015 , this relationship is quadratic and less strong $\left(R^{2}=76.56\right)$ than in 2013 and 2014. This confirms once again the importance of doing analyzes over several years to assess the performance of community networks.

\section{Conclusion}

This study allowed us to analyze the evolution of the performance of 05 community networks using six indicators which are: primary yield, rate of unpaid invoices (UI), linear distribution loss index (LDLI), the average annual network renewal rate (AANRR), the maximum connection opening time for new subscribers (MCOT) and a financial indicator which is annual income (AI). It is clear from these analyzes that the primary yield, the linear water loss index, the default rate, the average annual rate of network renewal and the annual revenue (AI) are very relevant indicators, having enabled the analysis of the performance evolution of each of the 05 community networks in Cameroon.

Overall, these analyses show a great influence of overall household consumption on primary output, but also on all the other indicators. In addition to this, this study showed the importance of community water supply networks to follow the linear unregistered volume index (LUVI) which is an important indicator to analyze; because it has harmful consequences on the functioning of the network by ricocheting its performance. This indicator should emphasize accuracy in reading, and billing meters reading, rigorously monitoring uncontrolled and prolonged leaks from the network as well as track water robbery, quantity of water consumed free of charge.

The AANRR is an investment indicator which is somewhat difficult to calculate at the level of community networks due to the fact that these networks struggle to ensure adequate maintenance. This rate was almost zero for the dif- 
ferent networks.

Annual income, also called turnover or amount received from subscribers over the year, is also a difficult indicator to grasp over the year; due to the fact that the consumption recorded at the level of community networks depends a lot on controlled and uncontrolled factors. The managers of these networks have difficulty keeping records with regard to consumers (what has been consumed, who has paid, how much has been paid, who is the owner, etc.), but also keep track of the unregistered Linear volume index (ULVI) A comparative analysis over three years of annual revenues has given us great dispersion around the annual averages. It seems important to use the average income over 3 to 5 years maximum to analyze the financial performance of said community networks.

Improving management efficiency requires mastering these indicators, which involves knowing how much money is spent to produce a particular quantity of water and how much is received as monthly income as per the amount received from subscribers. Is the community network capable of keeping good records of daily transactions and tracking system failures?

To do this, we recommend improving the monitoring of the points below in order to ameliorate the performance of community networks:

- Improve the invoice collection system: the time interval between receipt of invoices and payment is shortened;

- Reduction of linear loss of water which allows an increase in water sales which generate a financial gain;

- Mobilize income from authorized non-billed consumption (for example, local administration and traditional authorities who receive water for free);

- Improve the network expansion capacity thanks to an average annual network renewal rate of more than $1 \%$ year;

- Reduction in the rate of unpaid bills and unbilled water by ensuring rigorous customer monitoring.

- Regarding the technical performance of community water supply network, parameters such as primary yield, linear loss index and unpaid rate, it allows better evaluation of the performance of community networks. Analyses have shown that this improvement in technical performance requires an improvement in the functioning of the network, which itself respects the points below:

- Routine maintenance, including the rapid replacement of broken pipes, valve heads and old structures, taking into account the fact that arrangements are made to finance maintenance;

- Improved monitoring of apparent water losses.

This study showed that external factors influence the functioning of community water network, such as market failure which results in a water price which does not reflect the social cost, since elites and the administrations do not pay water. This leads us to say that the price per cubic meter of water does not indicate a strong signal to guide consumers, because we have observed strong dispersion around consumption averages. The hidden costs linked to the opportu- 
nity costs of an inefficient management, namely the high rate of unpaid invoices and significant water losses in the network (losses actually occurred during transit, volumes consumed not accounted for, reading errors, theft and actual loss); and finally the price of water, which does not cover management costs, deserves more attention from community network managers.

\section{Conflicts of Interest}

The authors declare no conflicts of interest regarding the publication of this paper.

\section{References}

Canneva, G., \& Guérin-Schneider, L. (2011). La construction des indicateurs de performance des services d'eau en France: mesurer le développement durable? Natures Sciences Sociétés, 19, 213-223. https://doi.org/10.1051/nss/2011157

Fellegi, I. P. (2003). Méthodes et pratiques d'enquête (p. 415). Ottawa, Canada: Centre de contact national de statistique Canada.

Günther, D. (2007). Success Factors for and Impacts of Participatory Approaches on Development of Management Indicators in IWRM (pp. 35-40). In The Conference "Earth System Governance: Theories and Strategies for Sustainability" 2007 Amsterdam Conference on the Human Dimensions of Global Environmental Change. Institute of Environmental Systems Research, Osnabrück, Germany: University of Osnabrück.

INS (Institut National de la Statistique) (2015). Rapport national sur les objectifs du millénaire en 2015: note de synthèse (p. 4). Yaoundé, Cameroun: INS.

Klein, R. J. T., \& Smith, J. B. (2003). Enhancing the Capacity of Developing Countries to Adapt to Climate Change: A Policy-Relevant Research Agenda. In J. B. Smith, R. J. T. Klein, \& S. Huq (Eds.), Climate Change, Adaptive Capacity and Development (pp. 317-401). London, UK: College Press. https://doi.org/10.1142/9781860945816_0014

Moussa, C., Fon, S., \& Fuh, M. (2010). Bridging the Gaps and Expanding the Scope for Sustainable Water Supply Systems: Experiences in Kumbo and Ndu Councils North West Region of Cameroon (p. 24). Bamenda, Cameroon: Cominsud and SNV.

Moussa, C., Togho, L. M., \& Abonge, J. (2011). The Elaboration of Municipal Water Policies and Strategies: Experiences in North West Councils (p. 26). Bamenda, Cameroon: Anembom and SNV.

OCDE (2001). Indicateurs environnementaux de l'OCDE: Vers un développement durable. Organisation pour la coopération économique et le développement (p. 155). Paris: OCDE.

Pannell, D. J., \& Glenn, N. A. (2000). Un cadre pour l'évaluation économique et la sélection des indicateurs de développement durable dans l'agriculture. Economie, Ecologie, 33, 135-149.

Riley, J. (2001). Multidisciplinary Indicators of Impact and Change: Key Issues for Identification and Summary. Agriculture, Ecosystems \& Environment, 87, 245-259. https://doi.org/10.1016/S0167-8809(01)00282-1

SNV (2012). Baseline des interventions de SNV dans les domaines de WASH, Energies renouvelables et PFNL (p. 164). Document de travail. Yaoundé, Cameroun: SNV.

WRI (1998). Watersheds of the World: An Assessment of the Ecological Value and Vulnerability of the World's Watersheds (pp. 15-20). Washington DC, USA: WRI. 